\title{
Voltage Control Method of Micro Hydropower Generators for Voltage Stabilization in Distribution Feeder with Renewable Energy Sources
}

\author{
Hudong LEE, Donghyun TAE, Daeseok RHO*
}

\begin{abstract}
This paper analyses the problem of voltage control by step voltage regulator (SVR) in the primary feeder with large-scaled PV systems, and presents operation ranges and the voltage control limit of micro hydropower generator (MHG) with power factor (PF) control function. In addition, this paper evaluates the voltage impact in primary feeders depending on voltage control modes of MHG, and then proposes an optimal voltage control algorithm. Furthermore, from the simulation results based on the proposed algorithm, it is verified that it can contribute to voltage stabilization in the distribution system with large-scaled PV systems.
\end{abstract}

Keywords: large scale PV system; micro hydropower generator; optimal voltage control; reactive power; voltage stabilization

\section{INTRODUCTION}

Recently, the government has started pushing a green growth policy as one of the next-generation industries, and also actively performing the demonstration project of $11 \%$ renewable sources among total energy by 2030 . According to the activity plan of renewable energy sources, local governments and renewable energy producers are actively installing and operating large scale PV systems in the distribution system. However, when the PV systems were interconnected and operated in distribution systems, many problems related to power quality such as voltage fluctuation in distribution system have occurred [1-5]. Under these circumstances, the power company has installed SVR in order to keep voltages of customers within allowable voltage limits in distribution feeders with PV systems [6, 7]. In addition, the distributed generations, renewable energy sources, should be kept at more than $90 \%$ of $\mathrm{PF}$ in accordance with the grid interconnection codes, and in case of technically necessary, the upper and lower limits of PF should be controlled according to technical guideline of the power company, and also PF of the distributed generations must not become leading PF at the point of distribution system which is lagging $\mathrm{PF}$ at distributed generations [8, 9]. However, despite such voltage regulators and technical guidelines, there are many problems associated with the voltage fluctuation and power quality when large-scaled PV systems and MHGs are connected with the distribution system. Therefore, this paper analyses the problem of voltage control by SVR in primary feeders with large-scaled PV systems and presents operation range and control limit of MHG with PF control function. And also, this paper evaluates the voltage impact in primary feeders depending on voltage control modes of MHG and then proposes an optimal voltage control algorithm. Furthermore, from the simulation results based on the proposed method, it is verified that it is effective and practical to stabilization of customer voltages in distribution system with largescale PV systems.

\section{CHARACTERISTICS OF VOLTAGE CONTROL OF DISTRIBUTED GENERATORS \\ 2.1 Voltage Control of SVR}

When large-scaled PV systems are operated in the distribution feeder $(22,9 \mathrm{kV})$, voltages at customers violate the allowable voltage limit due to the output of PV systems as shown in Fig. 1. To control the voltage, it is necessary to variate tap position of the pole transformer (P.tr). However, it is difficult to do it with the operation conditions of PV systems. Therefore, SVR is conventionally installed as one solution to overcome the voltage problem caused by PV systems. The operation type of SVR is categorized by LDC (line drop compensation) method, programed method and constant sending voltage method [10, 11]. In Korea, SVR generally adopts constant sending voltage method, but it is difficult to keep customer voltages within the allowable limits with load variation and feeder configuration [12].

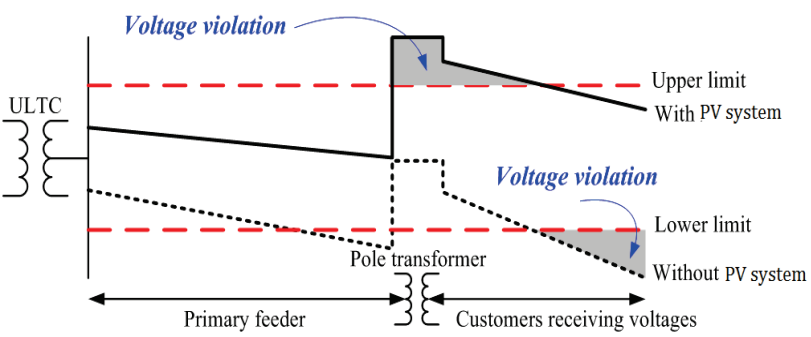

Figure 1 Customer voltage profile with operation of PV system

\subsection{Voltage Control by PF Operation of MHG 2.2.1 PF Conditions of MHG}

MHG needs to be kept at more than $90 \%$ of PF under the grid interconnection codes and also its PF does not need to become leading PF at point of distribution system which is identical with lagging $\mathrm{PF}$ at distributed generations. Therefore, a power company (KEPCO) usually sets operation condition of $\mathrm{PF}$ considering voltage characteristics in distribution feeders as shown in Tab. 1. In the case of A generator, its PF should be lower than $94 \%$ of leading, and in case of B generator, PF should be lower than $92 \%$ of leading depending on generator capacity [9].

Table 1 PF allowable limit of distributed generator by KEPCO

\begin{tabular}{|c|c|c|}
\hline Items & Capacity & $\begin{array}{c}\text { PF allowable limits } \\
\text { (based on the generator) }\end{array}$ \\
\hline A generator & $900 \mathrm{~kW}$ & lower than $94 \%$ of leading PF \\
\hline B generator & $1,500 \mathrm{~kW}$ & lower than $91 \%$ of leading PF \\
\hline
\end{tabular}




\subsubsection{Operation Range of Reactive Power with PF Condition}

According to the operation control range of $\mathrm{PF}$ to regulate voltage rising at $\mathrm{PCC}$ (point of common coupling), the actual output power of each MHG could be limited depending on rated capacity $[13,15]$. A generator in Tab. 1 can operate rated power from $85 \%$ to $94 \%$ of leading PF as shown in Fig. 2, but B generator can operate $40 \%$ of rated power, approximately $600 \mathrm{~kW}$, at lower than $91 \%$ of leading PF as shown in Fig. 3. Therefore, it is clear that output power of each generator is limited according to technical guidelines of PF operation condition and then the loss of power generation has occurred as shown in Tab. 2 .

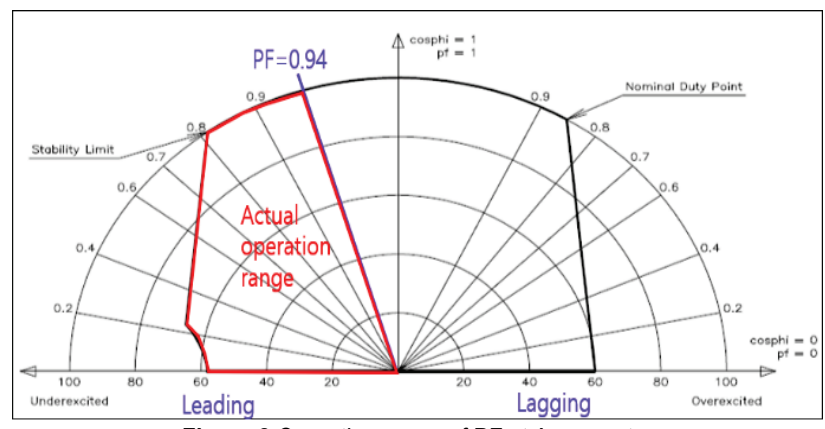

Figure 2 Operation range of PF at A generator

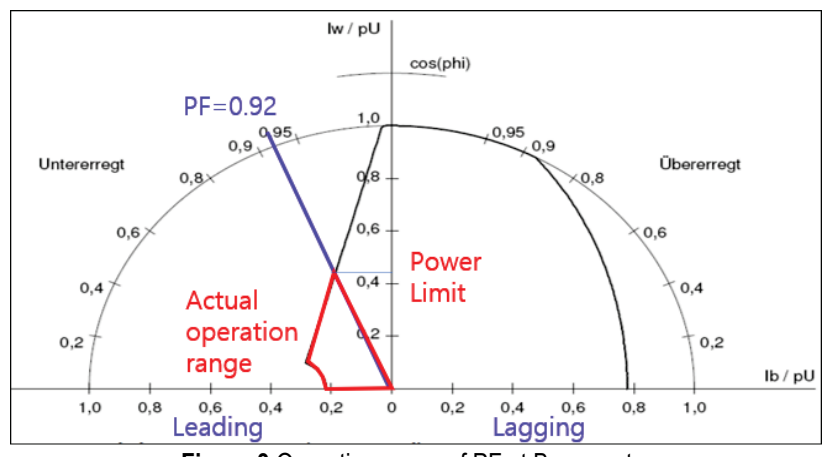

Figure 3 Operation range of $\mathrm{PF}$ at $\mathrm{B}$ generator

Table 2 Operation range of PF at each generator
\begin{tabular}{|c|c|c|c|}
\hline Items & Capacity & PF allowable limit & $\begin{array}{c}\text { Actual operation } \\
\text { range }\end{array}$ \\
\hline A generator & $900 \mathrm{~kW}$ & $\begin{array}{c}\text { up to } 85 \% \text { of } \\
\text { leading PF }\end{array}$ & $\begin{array}{c}\text { Rated power is } \\
\text { available }\end{array}$ \\
\hline B generator & $1500 \mathrm{~kW}$ & $\begin{array}{c}\text { up to } 90 \% \text { of } \\
\text { leading PF }\end{array}$ & $\begin{array}{c}\text { Rated power is not } \\
\text { available }\end{array}$ \\
\hline
\end{tabular}

\subsubsection{Characteristics of Voltage Control with PF Operation Condition}

As described above, MHG usually performs operation range of $\mathrm{PF}$ according to technical guidelines of KEPCO to regulate voltage at PCC. Namely, each generator absorbs reactive power and reduces system voltage at PCC [14]. However, the operation condition of PF in each generator is usually applied regardless of the PV system or load variation in the distribution system. Fig. 4 shows voltage variation at $\mathrm{PCC}$ according to the operation condition of $\mathrm{PF}$ in each generator [16]. Voltage profile (a) and (b) in Fig. 4 indicate voltage profile in primary feeder with PV systems, and (C) and (d) are voltage profiles without PV systems, and also (b) and (d) are voltage profiles with PF operation conditions of MHG. Since voltage profile in primary feeder with PV systems may be raised during the day as shown in (a), MHG can maintain customer voltage within allowable limit by reducing voltage at PCC with operation condition of $\mathrm{PF}$ as shown in (b). However, voltage profile in primary feeder with PV systems may be violated from the allowable limit during the night and heavy load of (C) by reducing voltage at $\mathrm{PCC}$ with operation condition of $\mathrm{PF}$ as shown in (d). Therefore, it is clear that operation condition of PF in each generator has a limitation of voltage control in distribution systems due to different one coping with the PV system or the load variation.

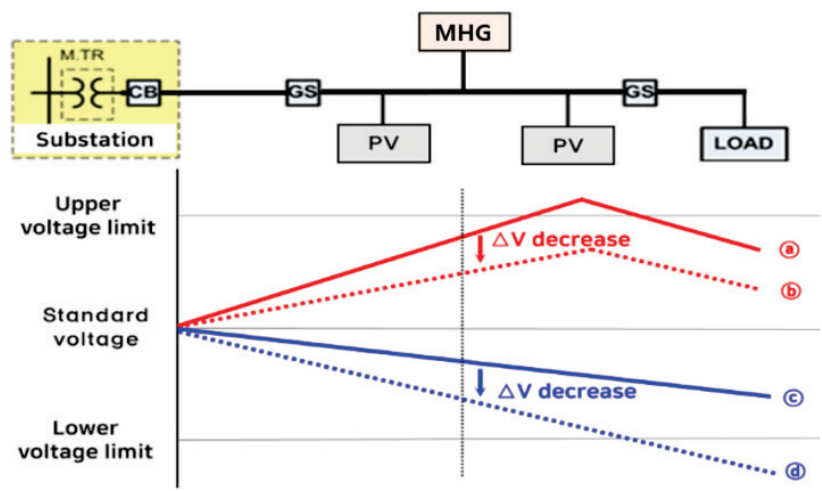

Figure 4 Voltage variation profile by PF operation range

\section{OPTIMAL CONTROL METHOD OF MHG FOR VOLTAGE STABILIZATION IN DISTRIBUTION FEEDER} 3.1 Characteristics of Optimal Voltage Control Mode

Generator voltage control modes of MHG installed and operated in Korea consist of control modes such as AVR and FCR and operation state mode such as OFF, PF and Var [15]. Tab. 3 shows voltage control modes for each MHG, which has different voltage control methods including $\mathrm{AVR} / \mathrm{OFF}, \mathrm{AVR} / \mathrm{ON}$ and AVR/Var modes. Characteristics of each control mode are demonstrated as shown in Tab. 3.

\begin{tabular}{|c|c|c|c|}
\hline $\begin{array}{c}\text { Power } \\
\text { plant }\end{array}$ & Capacity / MW & Generator voltage / $\mathrm{kV}$ & $\begin{array}{c}\text { Generator } \\
\text { control mode }\end{array}$ \\
\hline $\mathrm{A}$ & $1000 \times 3$ & 3,3 & AVR/OFF \\
\hline $\mathrm{B}$ & $1650 \times 3$ & 0,69 & $\mathrm{AVR} / \mathrm{PF}$ \\
\hline $\mathrm{C}$ & $1665 \times 3$ & 6,6 & AVR/OFF \\
\hline $\mathrm{D}$ & $1250 \times 4$ & 0,69 & AVR/PF \\
\hline $\mathrm{E}$ & $2500 \times 2$ & 3,3 & AVR/OFF \\
\hline $\mathrm{F}$ & $947 \times 3$ & 0,69 & $\mathrm{AVR} / \mathrm{PF}$ \\
\hline $\mathrm{G}$ & $1500 \times 2$ & 3,3 & AVR/OFF \\
\hline $\mathrm{H}$ & $1500 \times 2$ & 0,69 & $\mathrm{AVR} / \mathrm{PF}$ \\
\hline 1 & $1500 \times 2$ & 6,6 & $\mathrm{AVR} / \mathrm{OFF}$ \\
\hline $\mathrm{J}$ & $1500 \times 2$ & 3,3 & AVR/OFF \\
\hline $\mathrm{K}$ & $1500 \times 2$ & 0,69 & $\mathrm{AVR} / \mathrm{PF}$ \\
\hline $\mathrm{L}$ & $660 \times 4$ & 0,48 & AVR/VAR \\
\hline $\mathrm{M}$ & $1500 \times 2$ & 6,6 & AVR/VAR \\
\hline $\mathrm{N}$ & $770 \times 3$ & 6,6 & AVR/OFF \\
\hline
\end{tabular}

\subsubsection{AVR Control Mode}

AVR control mode is the most important mode of excitation system, which maintains a constant voltage of setting voltage regardless of voltage variation of PCC and output power of MHG. 


\subsubsection{Var Control Mode}

Var control mode is to constantly control reactive power of MHG according to set value, and then the voltage of MHG may fluctuate with the voltage at PCC and output power of MHG. Fig. 5 shows characteristics of reactive power controlled step by step from leading PF operation to lag PF operation. It is known that the voltage of MHG is decreased with reactive power. Fig. 5a is a profile of reactive power ranging from $300 \mathrm{kVar}$ to $-100 \mathrm{kVar}$, and Fig. $5 \mathrm{~b}$ is the voltage at PCC and voltage regulation of MHG according to reactive power variation.

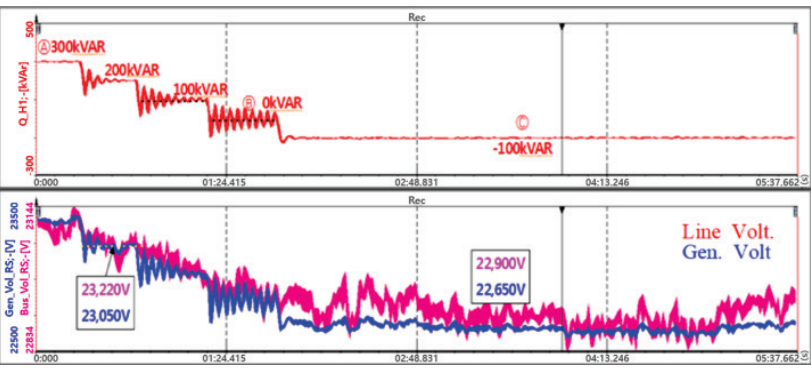

Figure 5 Voltage control characteristics in Var control mode

\subsubsection{PF Control Mode}

PF control mode is to constantly control PF of MHG according to set values, by adjusting active and reactive power. This mode is an operating method with set values of more than $90 \%$ of lagging PF under grid interconnection codes of distributed generators in KEPCO. Fig. 6 shows characteristics of reactive power and voltage of $\mathrm{MHG}$ according to step by step setting values of PF, where Fig. $6 \mathrm{a}$ is a profile of PF ranging from $-0,99 \%$ to $+0,95 \%$ and Fig. $6 \mathrm{~b}$ is the characteristics of voltage regulation with the PF variation.

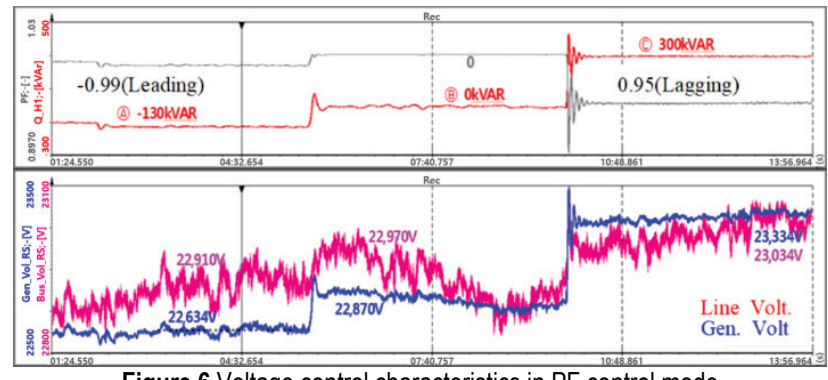

Figure 6 Voltage control characteristics in PF control mode

\subsubsection{Optimal Control Mode}

As described above, operation characteristics of the excitation system of MHG are being varied with control modes, and setting values of voltage control modes are different at each MHG. Also, to mitigate voltage variation at PCC when distributed generators are interconnected with a distribution system, leading PF operation of MHG is being required with the codes [9]. However, PF and Var modes of MHG is not enough to properly mitigate voltage variation at PCC because setting values of PF or Var are controlled with PV systems and load variations. If the voltage at PCC is higher than the allowable voltage limit, it can be reduced by leading the PF operation of $\mathrm{MHG}$, but if it is lower than the limit, it can be further lowered and then voltage problems of customers occur. However, AVR mode is the most effective one to mitigate voltage at PCC, which can constantly control voltage of generator with adjusting reactive power regardless of load and voltage variations.

\subsection{Optimal Algorithm of Voltage Control for MHG 3.2.1 Characteristics of Existing Voltage Control Algorithm}

As mentioned earlier, AVR mode among several voltage control modes is the proper control mode to mitigate voltage variation at PCC. However, this control mode also is not enough to properly mitigate voltage variation at $\mathrm{PCC}$. If system voltage at $\mathrm{PCC}\left(V_{\mathrm{L}}\right)$ is higher than the setting voltage $\left(V_{\mathrm{S}}\right)$, AVR mode is firstly to adjust voltage of MHG until the setting voltage after starting of generator, and to synchronize $\mathrm{MHG}$ at $\mathrm{PCC}$ with being compared to voltage at $\operatorname{PCC}\left(V_{\mathrm{L}}\right)$ and then voltage of $\operatorname{MHG}\left(V_{\mathrm{G}}\right)$ is constantly operated with variation of system voltage at PCC as shown in Fig. 7. Therefore, MHG may cause overvoltage at PCC according to its reverse power flow.

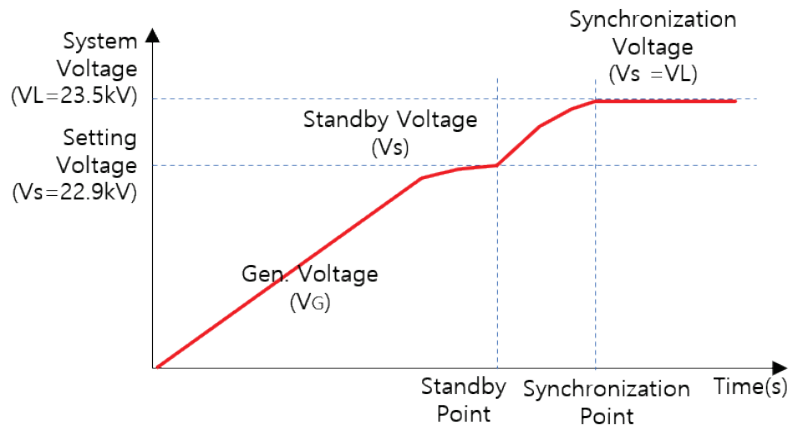

Figure 7 Concept of existing voltage control method

\subsubsection{Optimal Algorithm of Voltage Control}

Existing algorithm of voltage control is supposed to regulate voltage of MHG ( $\left.V_{\mathrm{SET}}\right)$ following the system voltage at PCC. The algorithm is not enough to properly mitigate voltage variation at $\mathrm{PCC}$ because voltage of $\mathrm{MHG}$ is normally determined according to voltage conditions at PCC with reverse power of PV systems and load variation. While voltage of MHG is synchronized and followed by variation of voltage at $\mathrm{PCC}$, the proposed algorithm is scheduled to properly regulate the voltage of MHG $\left(V_{\mathrm{SET}}\right)$ at set point regardless of voltage variation at $\mathrm{PCC}$ by replacing setting value of exciter with setting voltage in order to stabilize system voltage at PCC as shown in Fig. 8.

Therefore, the proposed algorithm of optimal voltage control is as follows.

[Step 1] Build up voltage of MHG $\left(V_{\mathrm{G}}\right)$ with initial set value $\left(V_{\text {pre }}\right)$ of exciter from starting point to standby point in Fig. 8.

[Step 2] Control voltage of MHG by synchronizer from standby point to synchronization point, which is constantly followed by system voltage of $\operatorname{PCC}\left(V_{\mathrm{L}}\right)$ regardless of system voltage variation.

[Step 3] Replace setting value of excitation controller with setting voltage $\left(V_{\mathrm{SET}}\right)$ if output of MHG is more than scheduled value from synchronization point to set point 
and then regulate the voltage of MHG to setting voltage with exciter control.

[Step 4] Regulate voltage of MHG within capability curve of output power, which is operated between OEL (over excitation limit) and UEL (under excitation limit).

[Step 5] Even if MHG violates capability curve of output power, the voltage of MHG is maintained with limited conditions.

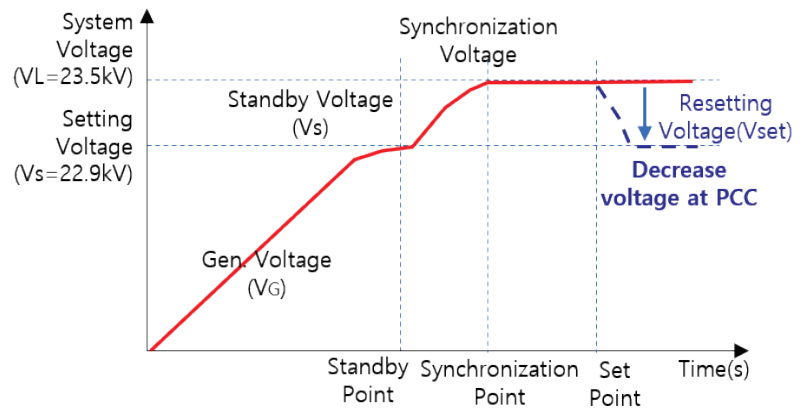

Figure 8 Concept of optimal voltage control method

Optimal algorithm of voltage control is demonstrated as shown in Fig. 9.

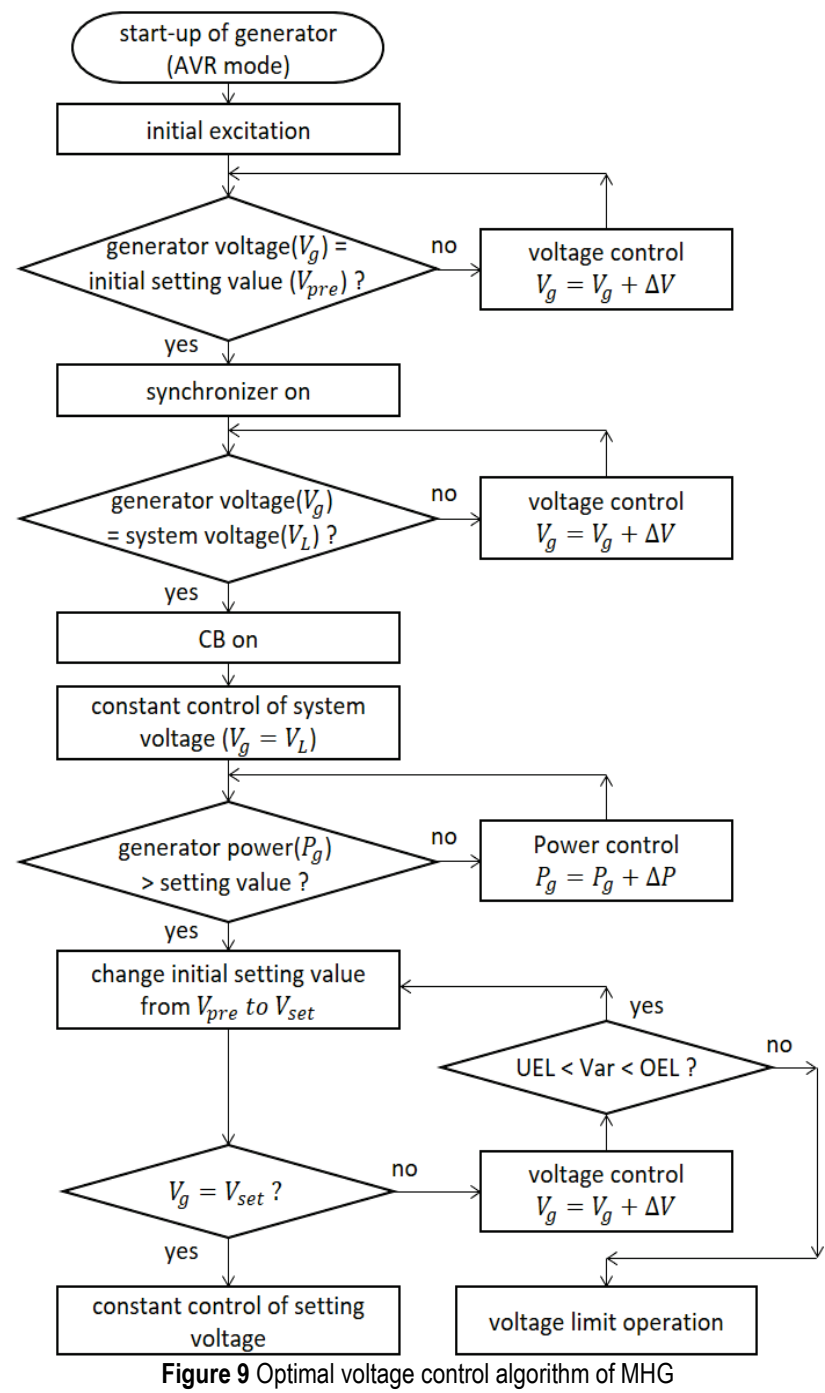

Figure 9 Optimal voltage control algorithm of MHG

\section{CASE STUDIES}

\subsection{Verification of Optimal Algorithm by Excitation System Simulator}

The proposed optimal algorithm of voltage control is implemented at existing simulator of the excitation system called RTS-7000, and its performance characteristics are demonstrated in Fig. 10. Fig. 10 shows the case where system voltage at PCC is higher than setting voltage of $\mathrm{MHG}$, which is characteristic of field voltage, field current, reactive power and voltage variation at MHG. Where, (1) of Fig. 10 shows synchronization point and (2) is optimal voltage control point. And also "Section I" of Fig. 10 is a section whose rated voltage of MHG is determined by field voltage and current after start-up and "Section II" is a section in which voltage of MHG is increased by supplying reactive power to follow system voltage at PCC after synchronization of MHG. Furthermore, "Section III" is a section whose rated voltage of $\mathrm{MHG}$ is maintained by absorbing reactive power with optimal voltage control if system voltage in the PCC is higher than one of MHG. Therefore, it is found that the proposed method is useful for voltage control in the distribution feeder.

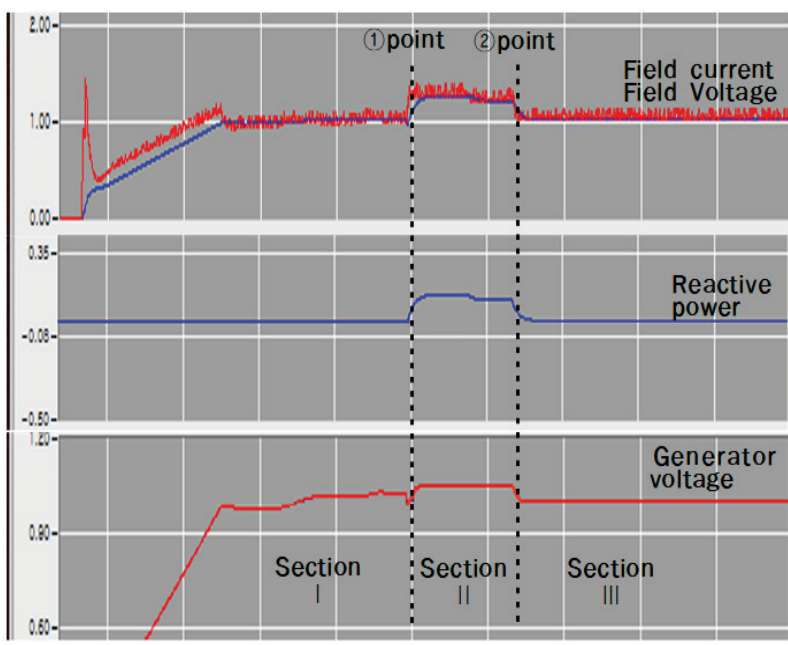

Figure 10 Voltage profile in case of higher system

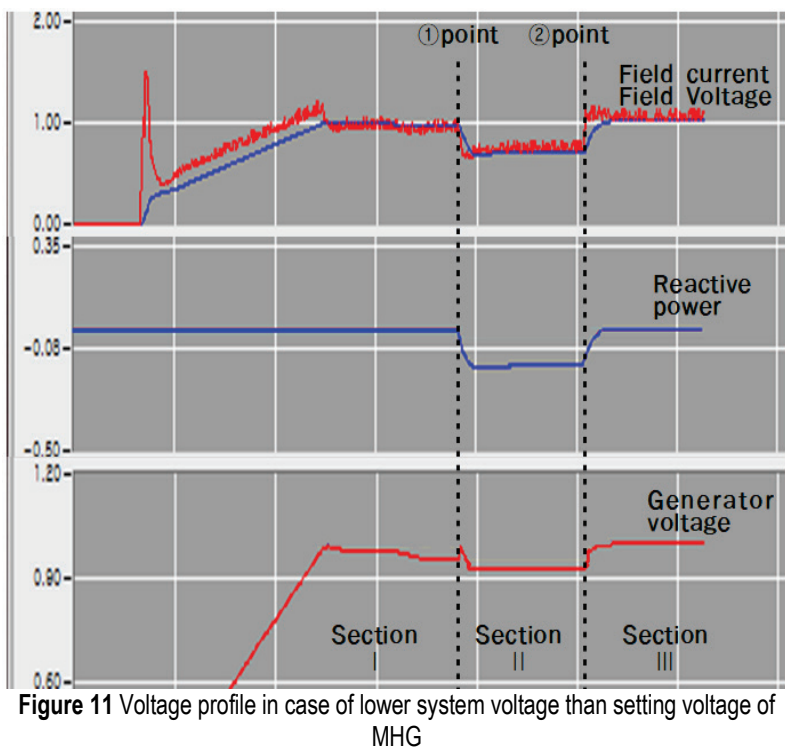

Fig. 11 shows the case where system voltage at $\mathrm{PCC}$ is lower than setting voltage of MHG. Field current and 
active power is controlled based on the optimal algorithm, and then system voltage at PCC can be maintained within allowable limit in section III as shown in Fig. 11. Therefore, it is known that the proposed voltage control algorithm of $\mathrm{MHG}$ is useful for voltage control in distribution system.

\subsection{Control Characteristics of Optimal Algorithm in Real System \\ 4.2.1 Simulation Condition}

Fig. 12 shows configuration of $Y D / L$ (distribution line) in $H S / S$ (substation) which is interconnected with large scale PV systems and MHG, as shown in Tab. 4. Specifically, the total length of $D / L$ is as long as $40,5 \mathrm{~km}$, and 1,8 MW of MHG is located at 13,2 km from $S / S$. And also, total of 6,3 MW of PV systems are installed through the $D / L$. Furthermore, a range of daily load profile is from 3,7 MW at off-peak load to 9,8 MW at peak load. Also, the voltage of the distribution feeder can be significantly maintained higher than nominal voltage when large scale PV systems are operated.

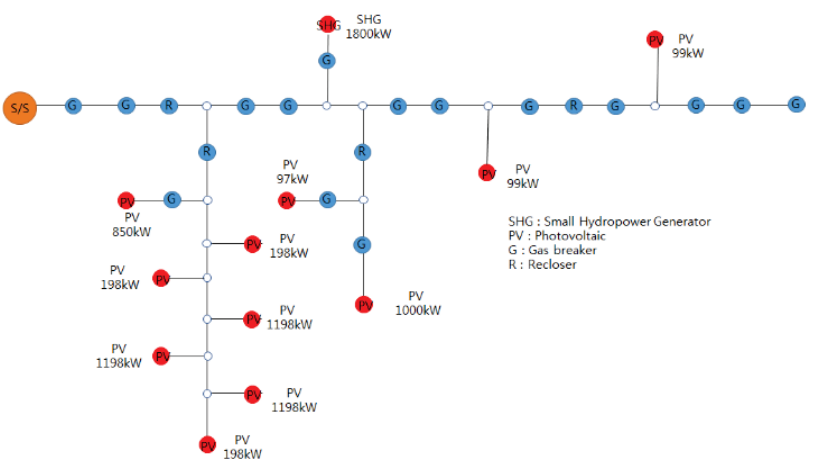

Figure 12 Real distribution system with PV systems

Table 4 Parameters of distribution line

\begin{tabular}{|c|c|}
\hline Items & Contents \\
\hline Main Feeder Length & $40,5 \mathrm{~km}$ \\
\hline Location Of MHG & $13,2 \mathrm{~km}$ \\
\hline Total Capacity Of PV Systems & $6,333 \mathrm{MW}$ \\
\hline Capacity Of MHG & $1,8 \mathrm{MW}$ \\
\hline Peak Load & $9,8 \mathrm{MW}$ \\
\hline Off-Peak Load & $3,7 \mathrm{MW}$ \\
\hline
\end{tabular}

\subsubsection{Control Characteristics of Optimal Algorithm}

Based on the proposed optimal voltage control algorithm of $\mathrm{MHG}$, voltage characteristics at PCC are demonstrated in Fig. 13.

Fig. 13a shows characteristics of the reactive power variation and Fig. 13b shows characteristics of voltage variation at $\mathrm{MHG}$ on condition that system voltage at PCC is $23,2 \mathrm{kV}$. Reactive power of generator is controlled from $17 \mathrm{kVar}$ to $-60 \mathrm{kV}$ ar by resetting the generator voltage to $23 \mathrm{kV}$ through the proposed optimal control algorithm of MHG. It is found that the system voltage at PCC is decreased to $23 \mathrm{kV}$. Therefore, it is clear that the proposed optimum voltage control method can constantly control voltage at PCC of MHG, and it can contribute to voltage stabilization of the distribution system even though a large scale PV system is operated.

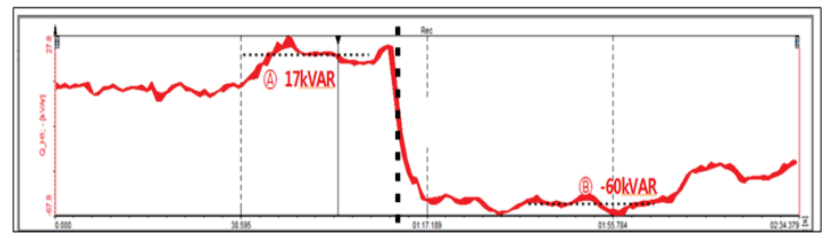

(a) Reactive power

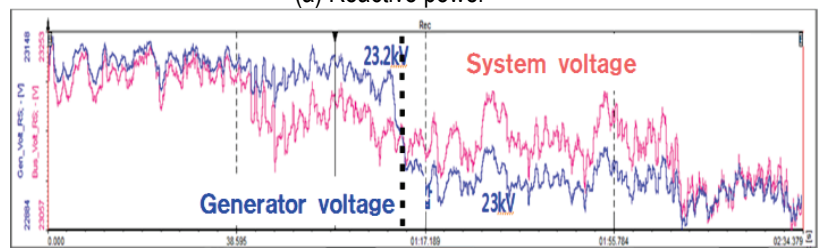

(b) Generator and system voltage

Figure 13 Characteristics of reactive power and system voltage

\section{CONCLUSION}

This paper proposes an optimal method of voltage control for MHG to overcome issues of voltage control in distribution feeders with large scale PV systems. In addition, this paper implements an excitation system simulator based on the proposed optimal control algorithm. From the proposed algorithm and simulator, it is confirmed that the system voltage is constantly maintained to setting voltage by controlling field current and reactive power if the system voltage at $\mathrm{PCC}$ is higher than setting voltage of MHG. Therefore, it is clear that optimal voltage control algorithm proposed in this paper can constantly control voltage at PCC even if large-scaled PV system is interconnected with distribution feeders, and the algorithm can contribute voltage stabilization of distribution systems. In the future, evaluation of hosting capacity for PV system is required depending on location of PCC and capacity of MHG based on the proposed voltage control method of MHG.

\section{Acknowledgements}

This work was supported by the power generation \& electricity delivery core technology program of the Korea Institute of Energy Technology Evaluation and Planning (KETEP) granted financial resource from the Ministry of Trade, Industry \& Energy, Republic of Korea (No. 20182410105070 and No. 20191210301940).

\section{REFERENCES}

[1] Park, J.-H., Lee, H.-D., Tae, D.-H., Ferreira, M., \& Rho, D.S. (2019). A Study on Disposal Diagnosis Algorithm of PV Modules Considering Performance Degradation Rate. Journal of Korea Academy Industrial Cooperation Society, 20(10), 493-502. https://doi.org/10.5762/KAIS.2019.20.10.493

[2] Kim, B.-K., Ryu, K.-S., Kim, D.-J., Jang, M.-S., Ko, H.-S., \& Rho, D.-S. (2018). Optimal Operation Method and Capacity of Energy Storage System in Primary Feeders with Step Voltage Regulator. Journal of Korea Academy Industrial Cooperation Society, 19(6), 9-20. https://doi.org/10.5762/KAIS.2018.19.6.9

[3] Son, H.-S.(2019). A Study on the Policy Improvement for Expanding New \& Renewable Energy. Journal of the Korean Institute of Illuminating and Electrical Installation Engineers, 33(2), 18-28.

https://doi.org/10.5207/JIEIE.2019.33.2.018 
[4] Jeon, W., Cho, S.-M., \& Cho, I. (2019). Estimating the Uncertainty of Net Load of 2030 Renewable Generation. Journal of the Korean Society for New and Renewable Energy, 15(4), 28-38. https://doi.org/10.7849/ksnre.2019.12.15.4.028

[5] Kwon, P. S. \& Kim, S. (2017). Scenario Analysis for the Achievement of the 2030 National Greenhouse Gas Reduction Goal in the Korean Electricity Sector. Journal of Environmental Policy and Administration, 25(2), 129-163. https://doi.org/10.15301/jepa.2017.25.2.129

[6] Kim, B.-K., Park, J.-B., Choi, S.-S., Jang, M.-S., \& Rho, D.S. (2017). A study on the voltage stabilization method of distribution system using battery energy storage system and step voltage regulator. Journal of Electrical Engineering and Technology, 12(1), 11-18. https://doi.org/10.5370/JEET.2017.12.1.011

[7] Kim, B.-K., Choi, S.-S., Wang, Y.-P., Kim, E.-S., \& Rho, D.-S. (2015). A study on the control method of customer voltage variation in distribution system with PV systems. Journal of Electrical Engineering and Technology, 10(3), 838-846. https://doi.org/JEET.2015.10.3.838

[8] Lee, W.-J. \& Oh, Y.-T. (2013). A Study on the Optimal Reactive Power Calculation Method of Induction Generator for Marine Small Hydraulic Power. Journal of the Korean Institute of Illuminating and Electrical Installation Engineers, 27(9), 100-107. https://doi.org/10.5207/JIEIE.2013.27.9.100

[9] KEPCO report (2011). A Study on the New Technical Guidelines for Interconnection Capacity of Distributed Generations in Distribution System, Korea Electrical Power Company, Republic of Korea.

[10] Lee, H.-O., Huh, J.-S., Kim, B.-K., Rho, D.-S., \& Kim, J.-C. (2014). Improvement Method of SVR Control in Power Distribution System Interconnected Distributed Generator. The Transactions of the Korean Institute of Electrical Engineers, 63(2), 224-229. https://doi.org/10.5370/KIEE.2014.63.2.224

[11] Lee, E.-M., Kim, M.-Y., Rho, D.-S., Sohn, S.-W., Kim, J.E., \& Park, C.-H. (2004). A Study on the Optimal Introduction of Step Voltage Regulator (SVR) in Distribution Feeders. The transactions of the Korean Institute of Electrical Engineers A, 53A(11), 610-618.

[12] Son, J.-H., Heo, S.-W., Rho D.-S., \& Kim, E.-H. (2011). Optimal Operation System of Step Voltage Regulator in Primary Feeders with Distributed Generations. Journal of the Korea Academia-Industrial cooperation Society, 12(6), 2698-2706. https://doi.org/10.5762/KAIS.2011.12.6.2698

[13] Alla, M., Guzmán, A., Finney, D., \& Fischer, N. (Mar. 2019). Capability Curve-Based Generator Protection Minimizes Generator Stress and Maintains Power System Stability. Schweitzer Engineering Laboratories, Inc.

[14] Kiprakis, A. \& Wallace, A. R. (2003). Intelligent Voltage and Reactive Power Control of Mini-Hydro Power Stations for Maximisation of Real Power Export. Waterpower XIII, At Buffalo, USA, 1-10. https://doi.org/10.13140/RG.2.1.3518.2800

[15] Davoud, E. M., Abbas S., Sajad, S., \& Davood, A. K. (2014). A practical method for calculation of over-excited region in the synchronous generator capability curves. IEEE International Symposium on Industrial Electronics, 727732. https://doi.org/10.1109/ISIE.2014.6864702

[16] Yan, C. \& Yongjun, Z. (2015). Application of DSTATCOM on distribution networks with small hydropower injected. 2015 Modern Electric Power Systems (MEPS), Wroclaw, 1-5. https://doi.org/10.1109/MEPS.2015.7477177

\section{Contact information:}

Hudong LEE, PhD Student

Dept. of Electrical, Electronics and Communication Engineering, Korea University of Technology and Education,

1600, Chungjeol-ro, Byeongcheon-myeon, Dongnam-gu, Cheonan-si, Chungcheongnam-do, 31253, Republic of Korea

E-mail: Ihd714@koreatech.ac.kr

Donghyun TAE, PhD Student

Dept. of Electricaln Engineering,

Korea University of Technology and Education,

1600, Chungjeol-ro, Byeongcheon-myeon, Dongnam-gu, Cheonan-si,

Chungcheongnam-do, 31253, Republic of Korea

E-mail: tdh2002@koreatech.ac.kr

\section{Daeseok RHO, Professor}

(Corresponding author)

Dept. of Electrical, Electronics and Communication Engineering, Korea University of Technology and Education,

1600, Chungjeol-ro, Byeongcheon-myeon, Dongnam-gu, Cheonan-si, Chungcheongnam-do, 31253, Republic of Korea

E-mail: dsrho@koreatech.ac.kr 